\title{
ELECTRONIC FULL-TEXT ARTICLES AS A SUBSTITUTE FOR TRADITIONAL INTERLIBRARY BORROWING
}

\author{
by \\ David Solar
}

\begin{abstract}
A Master's paper submitted to the faculty of the School of Information and Library Science of the University of North Carolina at Chapel Hill in partial fulfillment of the requirements for the degree of Master of Science in Library Science.
\end{abstract}

\section{Chapel Hill, North Carolina}

October, 1999

Approved by:

Advisor 


\section{Table of Contents}

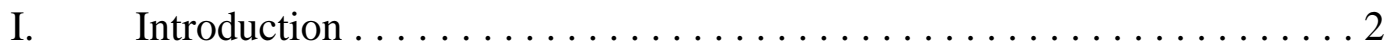

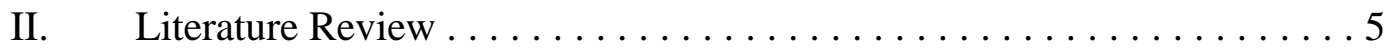

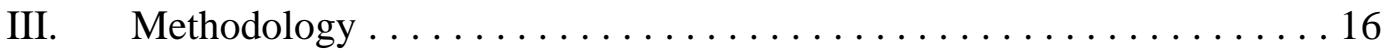

IV. $\quad$ Results .............................. 19

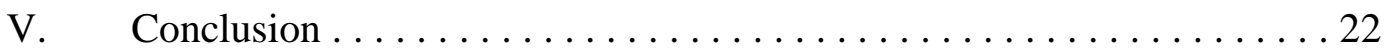

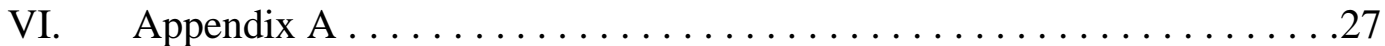

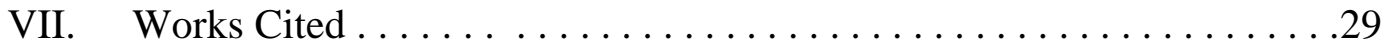




\section{Introduction}

The growth in availability of electronic full-text databases in academic libraries has now reached the point where users are regularly learning to check for full-text options when retrieving article citations. As the full-text backfile continues to grow, along with the constant addition of new journal articles, the potential for this new resource to alleviate the demands being placed on interlibrary borrowing departments within academic libraries needs to be seriously considered. Many full-text databases offer articles from journals that the university library may not subscribe to in print. Does the additional availability of these electronic full-text articles meet the demand for information not available from the library's print collection? Although at this time it is unlikely that the total number of interlibrary borrowing requests will show any decline as a result of the availability of electronic full-text, it may be possible to ascertain some indicators of the potential for these full-text databases to supplement interlibrary borrowing.

Traditional interlibrary borrowing of journal articles usually requires the borrowing library to request a photocopy of the article from another library or institution. Various procedures exist for doing this, but most large academic libraries place the request via OCLC or one of the other large electronic networks of shared bibliographic records. Although there may be fees involved in these 
transactions, very often the borrowing library will incur the cost and the user is provided the information free of charge. The main drawback to this system is the time it takes for requests to work their way through the interlibrary loan process. Although in most cases the turnaround time for a requested article to be received by a borrowing library is satisfactory to the user, in some cases it can be too slow and is almost always unpredictable. This distinguishes interlibrary borrowing from document delivery services which can often fulfill a request within 24 hours, but where a fee is directly charged to the user or institution.

This paper examines the ability of academic library users to substitute electronic full-text journal articles, accessed through online databases licensed by their library, for photocopied articles obtained through the traditional interlibrary borrowing process. Electronic full-text articles are essentially the online counterpart of print articles and are sometimes referred to as "full-image" documents when graphs and photos have been scanned in addition to the text. Scanning has provided a significant technological benefit to users in that it gives greater assurance that all parts of an article have been reproduced. Formerly, "full-text" did not necessarily mean that a user would find everything that had appeared in the original print version. In this paper, "full-text" refers to either a text-only or image reproduction, depending on the database used.

Another distinction needs to be made between electronic journals and electronic full-text articles. Electronic journals are commonly recognized as "publications" existing solely in an online format. Therefore, it is unlikely that users will place an interlibrary borrowing request for a journal of this type. 
Similarly, an electronic version of a print journal may exist independently in that most of the "articles" in the electronic version will be different from those appearing in print. This study examines electronic full-text articles that are at least identical text copies of existing print versions.

Many academic research libraries now provide access to electronic fulltext databases from their online catalogs. At the University of North CarolinaChapel Hill, for example, a selection of databases linked from a central library website serve as "gateways" to articles from a variety of disciplines and publishers. The companies that create these gateways are often referred to as "aggregators," comprising subscription agents, database vendors, index and abstract publishers, or even primary publishers. While most aggregators are thirdparty vendors (e.g. UMI, IAC, EBSCO, SilverPlatter, OCLC, CARL, Blackwell, Elsevier/CIS,) that combine the journals of multiple publishers, some such as IDEAL from Academic Press aggregate the publisher's own electronic titles into a single package (Webb 202). The databases offered at the University of North Carolina Libraries are provided through just such a collection of gateway systems contracted from among a number of commercial aggregators. Through these gateways, users may access citation and abstract databases as well as several databases containing full-text journal articles. Once they have located a desired article, the user can either print a full-text copy or in some cases have it sent via fax or email. 


\section{Literature Review}

Although electronic full-text has been available for a number of years, it is with the design of improved gateway systems that users have found it easier to access this type of format. The relative ease of use, the growth in the amount and variety of articles to be found in online databases and the effort by libraries to promote this format have all enhanced the role of electronic full-text as an alternative information resource. Nonetheless, it was not expected that there would be many studies found in the library science literature measuring the impact of electronic full-text on traditional library services. This is because of the relatively recent implementation of this resource by libraries and the difficulty of measurement due to the number of disparate databases and its constantly evolving nature. In examining the literature for this study, the focus was on recent articles touching on electronic full-text and interlibrary loans found in both traditional library journals as well as the more technologically-oriented publications for information professionals.

Writing in Serials Review, George Machovec (1977) discusses the advantage provided by aggregators, such as the inclusion of titles in their database to which a library does not already subscribe. Using the example of Academic Press, which offers its 176 titles to library consortia, Machovec demonstrates how this database allows more complete access to the company's electronic journals to consortia libraries that did not previously own many of the Academic Press titles.

Smaller academic libraries may especially benefit from access to databases available through a consortium since their journal collections are 
generally not as comprehensive as the collections maintained at the larger

institutions. One observer who is particularly optimistic regarding the potential of

full-text access provided through consortial arrangements is Lars Bjornshauge:

Increased user access to information instantly will quickly reduce the demand for staff involved both with document supply from the library's own stock and with interlending activities. The positive scenario is where libraries, whether regional, national or international, establish a number of overlapping consortia which can provide their users with an enormous virtual collection of scientific information to which access is available electronically. In this scenario, the concepts of lending, borrowing and interlending are obsolete as far as current material is concerned although for older material, books, etc., they would still have a part to play. (32)

Some observers, however, see a possible disadvantage arising from consortial arrangements, especially if the inclusion of titles to which a library does not subscribe means that the library is paying for a resource that it does not need (Webb). Webb also believes that “. . . because there are still relatively few ejournals, the offerings of various aggregators overlap dizzyingly, making analysis of the various offerings extremely laborious and time-consuming" (202). Calling attention to the distinction between electronic journals and aggregations of fulltext articles in electronic databases, Daniel Jones finds that not all aggregators include the entire contents of a journal issue in its electronic article collection. Furthermore, electronic information is not always "fixed." Aggregators may lose the rights to continue to provide content from a particular publisher, meaning libraries risk losing full-text access to articles provided by that publisher (Webb 202).

One development that could promote the use of electronic full-text would be the design of an integrated gateway allowing users to search across several 
databases simultaneously. Currently, users may need to access several separate databases using different search interfaces for each one. Having an integrated search interface will require agreement among a large number of parties, each having slightly different interests, and including publishers, database aggregators and libraries among others. This presents a formidable barrier to realization, but one that might be worth working to overcome.

Writing in 1993, Shirley Baker and Mary Jackson speculate that having these full-text databases available through local online catalogs might even minimize the number of traditional interlibrary loan requests (6). Taking this a step further, Minna Sellars and Joan Beam found that in the related realm of commercial document delivery, "While a single electronic interface for all user requests remains a goal, the current environment has not yet provided an integrated system of databases with multiple vendors and networks linked to local library holdings. This feature is likely to be the key to the success of library partnerships with commercial electronic services" (465).

Another development tending to promote the use of electronic full-text is having links from the library online catalog to available full-text databases. Looking at this issue from a more practical standpoint however, Julie Rabine and Linda Rich raise several important questions in relation to the creation of WebOPAC records linking to available full-text "holdings." They wonder, “. . W With all of the disadvantages noted above for aggregator products, should a library catalog the individual titles in a large package? Who will monitor the shifts in content? Will the vendor guarantee some stability in the network addresses? 
Should the catalog point to individual titles or to a vendor's homepage, and does the library even have this choice?" (279). These are all questions that will also need to be resolved if electronic full-text is to achieve greater prominence among the information resources in the academic library.

While libraries and content providers must continue to work together in resolving these issues, Carol Tenopir believes that the goal of integrated searching of full-text resources is close to becoming a reality ("Data dealers"43). She finds that links to full-text have become both routine and expected by library users and that within the next couple of years we will see many more integrated products providing access to commercial databases and full-text, all under one interace. Many information professionals have speculated as to the impact that newer technologies are likely to have on traditional library services, with several suggesting a reduction in traditional interlibrary loan activities as a result. Looking at the electronic library of the future, Mounir A. Khalil believes that, "Now we can envision, when the electronic library exists in the future, there will be no interlibrary loan services because there is no need for them" (198). However, Yem Siu Fong sees a changing need for interlibrary loan librarians in the electronic age more as facilitators to connect users to information resources using computer technologies (23). Similarly, Chandra Prabha and Gay N. Dannelly state that, "With the advent of electronic catalogs, the development of the Internet, and contractual access to resources provided by commercial vendors, the entire nature of library service, resource provision, and the independent library 
user are changing radically. Ideally this will decrease the intervention previously required," while not necessarily eliminating it altogether (367).

Directly addressing interlibrary borrowing services, Mary Jackson writes that in the nearer term, "Both options [full text or full image] permit patrons to access documents directly, and, as with ordering from commercial document delivery suppliers, offer the potential to moderate the sharp increase in interlibrary loan volume" (46). This belief is shared by Lorraine Haricombe, who finds that, 'Libraries support users' direct access to numerous vendor databases and other information resources, eliminating the need for interlibrary loan staff to mediate such transactions" (2). At Wichita State University, it was discovered at their library that, "Through the explosion in commercial document delivery services, full-text systems, and Internet access, many more information access points are available without ILL intervention in the process" (Naylor 52).

A relatively early study that examined the impact of electronic full-text on traditional interlibrary borrowing was conducted by Adele Bane at Penn State University’s Great Valley campus in 1995. In this study Bane found that over $42 \%$ of the campus library patrons were able to get at least $50-75 \%$ of the articles they needed using Business Periodicals Ondisc (BPO). This is a full-text CDROM database of approximately 400 titles indexed in ABI/Inform, and was well suited to she school's emphasis on business and management courses. Bane also found that an additional $30 \%$ of library users were able to retrieve $75-100 \%$ of the articles they needed using this source, while a minority (46\%) used traditional interlibrary loan to get articles not available on BPO. A three year review of 
interlibrary loan requests at the Great Valley campus library demonstrated the reduced demand for interlibrary borrowing services as a result of the implementation of this resource.

While the above study is interesting in the context of a smaller academic library whose user population consists of a more specialized community of students, Bane acknowledges that content was clearly secondary to convenience in the use of BPO by students at the Great Valley campus library. This fact makes the study somewhat less relevant to the situation at a large research library, such as at Penn State's State College campus or here at the University of North Carolina-Chapel Hill. The emphasis at a larger academic library is more likely to be on scholarly research and users are more likely to require interlibrary borrowing services for the relatively obscure journal articles found outside the library's collection. Nonetheless, it is interesting to have an example of a library where electronic full-text was found to have a measurable impact on the level of interlibrary borrowing services.

One widely observed phenomenon associated with the introduction of electronic resources has been the concomitant growth in demand for a greater variety of materials. First observed upon the introduction of CD-ROM, and continuing with internet access to the catalogs of other libraries, and especially with the growth of electronic indexing and abstracting databases, users are increasingly able to locate more materials, more easily, from among the world's storehouses of information. In Bane's study above, she remarks that, "The great unknown for many libraries is whether access to full-text CD programs will 
increase or decrease the demand for the journal on site. A related topic is the impact of full-text access on the volume of ILL requests" (54). The growth in bibliographic resources and the ease with which users are able to retrieve citations has clearly led to an increase in demand for interlibrary loan services. This increased demand for traditional interlibrary loan services, experienced at many large academic libraries, may even offset or exceed any potential reduction in interlibrary borrowing as a result of the availability of electronic full-text. The best that may be hoped for is a blunting of the effect of growing demand (Medina and Highfill 29).

A common lament in much that has been written on the role of electronic full-text in supplementing interlibrary borrowing has been the lack of sufficient full-text availability, especially in light of the growing volume of requests noted above. In a 1993 study at Stetson University, David Everett compared interlibrary borrowing requests for journal articles with a list of full-text journals found in Fulltext Sources Online. The result was a very small number of article requests that could be matched with an electronic full-text counterpart. Reporting on these results, Everett envisions full-text databases as a fast and convenient alternative to traditional interlibrary borrowing in the future, but finds that at present:

... The titles online are likely to be already available in a library, while the scholarly journals needed by interlibrary loan patrons in an academic library are unlikely to be online in full-text. At this point, full-text databases have little to offer interlibrary loan librarians as a supplemental document delivery system. There simply are not enough titles available on any one service to fill a large number of requests ... Until full-text databases come closer to matching the breadth and depth of ILL patrons' needs, the document delivery potential of full-text databases will remain just that - potential (24). 
In a more recent article, Medina and Highfill echo Everett's conclusions. They too believe that, "Alternatives for library-to-library lending, such as those provided by full-image or full-text databases and commercial document suppliers, may meet demand for many current and selected retrospective serial materials. However, it is unlikely that either will meet the need for most historical items because few materials of this type have been converted to electronic format nor are they likely to be" (29). One would hope that the situation is improving with the growth in availability of full-text databases. However, as recently as last year, Stephen Prowse writes that, "The threat to traditional ILL posed by electronic journals is modified by the fact that they tend to predominate in STM [scientific, technical and medical journals] and only cover very recent years" (85). Similarly, Mary Jackson finds that, "Since most electronic resources cover new titles or the past two or three years of existing titles, using them as a substitute for ILL remains more a potential than a reality" (46). This factor continues to affect the impact that electronic full-text can be expected to have on interlibrary borrowing services.

In response to this limitation, Carol Tenopir has reported the good news concerning UMI's Digital Vault Initiative (DVI), an ambitious project to address the need for a full-text backfile ("Recapturing the past online"). While this ongoing project is not yet available for study, DVI's ultimate goal is to provide access to five and a half billion page images of older materials with access provided through UMI's ProQuest Direct. Depending on the extent of the available backfile and the fees charged for libraries to access this information, 
DVI could be part of the answer leading to significantly greater use of electronic full-text resources in place of traditional interlibrary borrowing in the near future.

A recent example of where full-text databases have had a significant impact on interlibrary loan requests has been observed at Eastern Washington University. In her study, Suzanne Milton states, "My daily involvement with patrons at the reference desk and in the classroom, coupled with my collection development responsibilities, serve to reinforce my impression that the availability of full-text articles has had a noticeable impact on interlibrary loan activities" (18). This was confirmed in the study, which found a noticeable reduction in borrowing requests corresponding with the school's introduction of two full-text databases in September of 1997 (UMI ProQuest Direct and Academic Ideal). During the latter half of 1997, ILL activity dropped to 1,650 requests versus 2,756 in the first half of 1997 . At the same time, UMI provided statistics on ProQuest Direct usage and reported that in September [1997] 67 articles were printed, 1,126 in October, and 7,408 in November. As Milton remarks, "This is quite a staggering increase in full-text usage and represents the most significant factor that has contributed to the decline of ILL activity" (19).

However, Milton also notes that the ability to generalize from the results of her study is qualified by both the relatively small size of the Eastern Washington University Libraries and the predominantly undergraduate and commuter student population. This is similar to the situation at the Penn State Great Valley campus in the Bane study reported above. The smaller size of the library journal collections at these universities makes it more likely that what is 
available in electronic full-text will be something that the library would otherwise have had to borrow. In addition, an undergraduate commuter student population will generally not require the same breadth of journal titles as students at a larger research institution. As Suzanne Milton notes, often what these students are able to find available from the Eastern Washington University Libraries is sufficient for completing their assignments. "With each addition [of electronic journal access], positive patron reaction was primarily a result of the immediacy of the results" (18). Finally, and in keeping with the theme noted above, Milton concludes her study by acknowledging that, "Electronic full-text, as yet, is unable to fully meet all the needs of our research population. Until full-text can approximate what is available in print for both serials and monographs, the need for interlibrary loan services remains" (19).

One factor that is likely to increase the potential of electronic full-text having an impact on interlibrary borrowing is the occasionally observed tendency for borrowing requests to be for recent articles (published within the past five years). In an OCLC study of commercial document suppliers, at least two-thirds of the article requests sampled were for articles published within five years of the study (Prabha ). Prabha states, "The overwhelming demand for recent articles suggests that, in the long run, the stress ILL/DD units face may perhaps lessen as periodicals released in full-text via online or CD-ROM grow in number" (567).

However, other studies have uncovered a different tendency. Mary Jackson finds that, "Analysis of OCLC ILL requests confirms that one-half of all photocopy requests are for materials older than 10 years - materials unlikely to be 
found in electronic format" (46). This approximates the casual observation of the records examined for this study, which revealed a large number of requests for articles older than five years. The percentage of requests for recent articles may be lower at a large academic research library, such as the University of North Carolina's Davis Library, than for all the types surveyed in the OCLC study. In any case, this is an area where further study might help to determine the impact that available electronic full-text can be expected to have on interlibrary borrowing.

In summation, the few studies examining electronic full-text from the perspective of interlibrary loan operations have generally found that the potential still exceeds the reality in terms of its being able to substitute for interlibrary borrowing requests. The lack of a sufficient number of journal titles and the absence of a deep enough backfile are cited as the two main reasons limiting the usefulness of this format. However, as several studies conducted at university libraries serving a smaller or more specialized user population have shown, electronic full-text may be having a greater impact where the research requirements are not quite as scholarly. Also, several observers see consortial arrangements as another means of providing access to a larger number of titles, thereby enhancing the role of electronic full-text in academic libraries.

The amount of current literature on this topic was discovered to be small, due in part to the relatively recent incorporation of electronic full-text gateways onto library web pages as well as the issues involved with their access. Additionally, electronic full-text databases themselves are still a new tool for both 
librarians and users, and are in a constant state of growth and development. Both reasons help explain the lack of studies examining the role of electronic full-text in the academic library. It is hoped that this study can provide a more current analysis of the potential for electronic full-text to supplement traditional interlibrary loan services.

\section{Methodology}

The method used in this study to measure the impact that electronic fulltext databases may have on interlibrary borrowing was to match journal article requests against their availability in full-text. Using article requests placed at the University of North Carolina's Davis Library, the percentage of borrowing requests that could have been filled through the use of full-text databases can be measured. This assumes that the user at a large academic research library has access to what is currently available through electronic full-text databases similar to those at the University of North Carolina. Measuring this percentage over three successive time periods also provides a look at any trend that might indicate the potential for these databases to reduce the volume of interlibrary borrowing requests. The expectation at the outset of the study was that the percentage would increase in each succeeding time period as more full-text articles become available, the archive or backfile of existing articles grows, and users become more aware of the existence of these databases.

The University of North Carolina Libraries offer access to full-text articles through links available from the main page of the online catalog 
(www.lib.unc.edu/). These links are labeled "Electronic Databases and Indexes" and "Electronic Journals," and provide connections to licensed commercial databases (see Appendix A for a summary of each database used in this study). These databases comprise the gateways mentioned earlier in this paper, since it is through them that users have access to an aggregated collection of journal titles that span a range of disciplines and publishers. The databases are available from any networked computer on campus, and have recently been made available from remote locations via a proxy server, which should eventually increase the level of usage.

In order to get a large enough pool of photocopy requests from which to sample, I was allowed to use the interlibrary borrowing requests for journal articles placed through the Interlibrary Borrowing Department at Davis Library, the main library on the University of North Carolina campus. Using these records also yielded a large cross-section of requests across disciplines, since users at Davis Library are generally students or faculty with varying research requirements and departmental affiliations. Davis Library also handles the borrowing requests from a number of the other departmental libraries on campus, which further lends to the breadth in the types of articles that are requested. Using these records provided an indication of the extent to which electronic full-text databases can supplement interlibrary borrowing services in an academic library where a large variety of borrowing requests are likely to be made.

For this study borrowing requests dating back to 1997 were examined. This allowed a three-year comparison over the period 1997-1999. Using this data, 
an attempt was made to identify a trend in the number of requests that could be matched with electronic full-text availability of the same article. In terms of the rapidity with which full-text articles are being put online, three years in "online time" was considered sufficient in terms of being able to suggest a trend in this regard. Furthermore, it is only in the past few years that full-text databases have experienced such rapid growth in content, so that prior to 1997 it is not likely that users would have found as much available.

In order to manage the large number of interlibrary borrowing requests placed through Davis Library, only those requests made during the months of January through May were examined for each of the three years. This also coincides with the spring semester of the academic year, when there is generally a high demand for borrowed and photocopied materials. It was not considered necessary to examine an entire year's worth of requests, since the study is measuring percentages and a larger sample size of requested articles would not affect the relative percentage of full-text matches from year to year. A January through May sample can be considered a useful representation of the type of articles that are likely to be requested throughout the year.

Additionally, only those titles with a 1992 or more recent publication date were included in the study. Although several of the databases contain articles originally published in print prior to 1992, a preliminary exploration of these databases revealed that it is relatively rare to find them. Therefore, requests for articles published before 1992 were excluded. Other requests excluded from the study were those for articles in journals already held at one of the campus 
libraries, as users in this circumstance are generally notified by the Interlibrary Borrowing Department as to their on-campus availability. However, where it appears that an article request of this type was processed anyway, the availability of the requested article in an online version was counted. The reason for this is that if the user or library staff member had been aware of the additional electronic availability of this title, a borrowing request would not have been made and the benefit of electronic access would have been realized. Finally, articles requested from the same volume/year of a particular journal were only counted once, in order to prevent giving disproportionate weight to any one title that may or may not have been available in an electronic version.

\section{Results}

In the first period examined for this study, January-May 1997, a total of 237 photocopy requests for articles published in 1992 or later were processed at the University of North Carolina's Davis Library. Of these, 23 were matched with electronic full-text articles available from one of the databases licensed by the university libraries. This comprises just under $10 \%$ of the requests.

For the January-May period of 1998, the total number of photocopy requests increased to 355 . Of these, there was a slight increase in the number of available full-text articles to 28 . As a result of the much greater increase in total requests, the actual percentage of matching full-text articles declined to just under $8 \%$. The surge in photocopy requests outpaced the growth in available full-text (see Fig.1). 
In the most recent period examined, January-May 1999, the total number of photocopy requests again grew significantly, this time to 484 requests. However, this was also followed by nearly a doubling in the number of available full-text articles to 50 . This amounts to $10 \%$ of total requests for articles published in 1992 or later.

\begin{tabular}{|c|c|c|c|}
\hline Year & Photocopy Requests & Available Full-Text & Percentage \\
\hline 1997 & 237 & 23 & .097 \\
\hline 1998 & 355 & 28 & .078 \\
\hline 1999 & 484 & 50 & .103 \\
\hline
\end{tabular}

Fig.1 - Relationship of Number of Borrowing Requests and Available Full-Text Articles by Year.

This observed doubling in the number of available full-text articles is in line with the initial expectation that both the addition of more full-text titles within databases and the relatively greater backfile of existing articles should grow to more reliably meet user demand. However, the dramatic increase in the number of overall borrowing requests, as represented graphically below, is keeping electronic full-text from having a greater impact on traditional interlibrary borrowing. 
Fig. 2 - Full-Text Availability Compared to Photocopy Requests

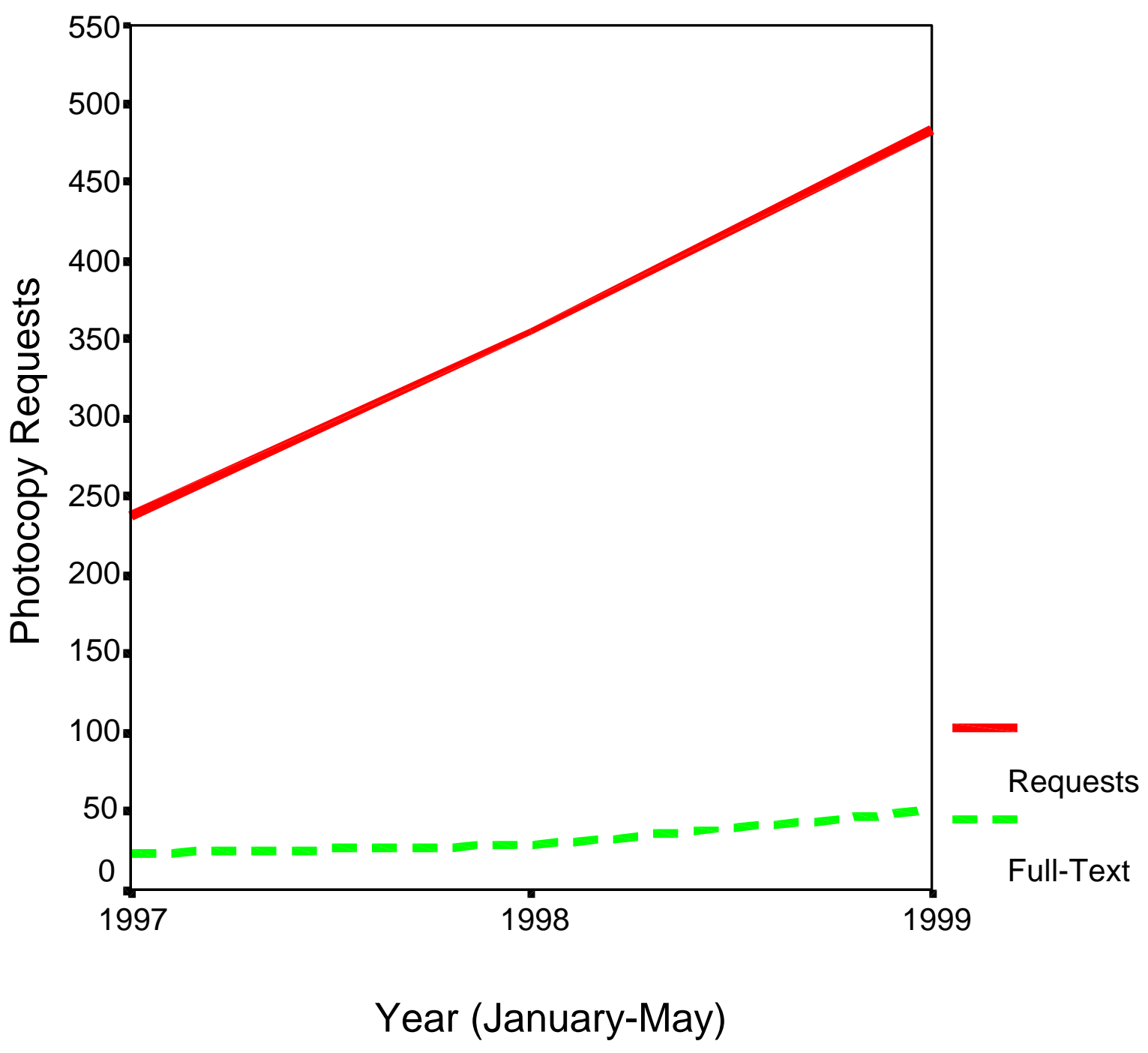




\section{Conclusion}

The data for the last period examined is encouraging in that it demonstrates a significant increase in full-text availability to users. Although the full-text as a percentage of total borrowing requests is not a dramatic number in any of the periods studied, it has increased between 1997 and 1999 and probably reflects an increase in the number of full-text journal titles being added to electronic databases. This researcher believes that as the available "archive" of full-text materials grows, electronic journals will have a larger role to play in fulfilling the research needs of researchers and students. Although a large percentage of articles requested through interlibrary borrowing are published within five years of the date of the request, many journals were omitted from this study because of a publication date prior to 1992. Assuming the continued electronic existence of the full-text articles currently available, although by no means guaranteed, there should be a greater pool of full-text articles comprising a backfile for the future researcher to access.

One factor that had an impact on the results was the significant increase in the total number of interlibrary borrowing requests made from one year to the next. As noted earlier, this trend is occurring at most libraries, as users find it easier and more efficient to search electronic databases. These databases are capable of much faster retrieval of citations than their print counterparts, which has led to an increase in user demand for interlibrary borrowing services. This trend is likely to continue with the growth in information and improvements in 
retrieval software. There will need to be dramatic growth in the number of fulltext titles if they are to even keep pace with the increase in interlibrary borrowing requests.

Related to this, it is also useful to comment on the breadth of journal title requests placed through a typical interlibrary borrowing department at an academic research library. As emphasized above, in order for electronic full-text documents to have any appreciable impact on interlibrary loan levels, a wide range of titles needs to be available. If interlibrary borrowing requests were placed for only a handful of titles, then the library could simply purchase these titles to meet user demand and reduce the need to borrow. The reality is that requests for journal articles via interlibrary borrowing are spread thinly over a large number of different titles, with only a small percentage being requested more than a few times in a given year. This has been observed in several studies involving interlibrary loan usage statistics (Beam; Prabha and Marsh). The availability of a large number of full-text journal titles is necessary in order for there to be any appreciable impact on interlibrary borrowing. As this and other studies have demonstrated, the number of available full-text titles is a long way from matching the variety of different titles typically requested in a large academic library.

One of the difficulties in trying to assess the potential of full-text articles to substitute for interlibrary borrowing is that we are attempting to account for something before it has happened. Library users who are able to avoid placing an interlibrary borrowing request by having access to electronic full-text databases 
are difficult to identify. Without a means of tracking the full-text articles being accessed by the user, it is difficult to measure the extent to which electronic fulltext is already being used in place of traditional interlibrary borrowing. It is likely that some users have already been using this access in place of traditional interlibrary borrowing. However, at this time the number who have done this is probably small.

A related question, outside the scope of this paper, is the extent to which users are willing to use full-text articles simply because they are readily available. The studies by Milton and Bane both found that traditional interlibrary borrowing declined with the implementation of electronic full-text databases as users became willing to trade content for convenience. This may also be occurring in larger academic research libraries, although the greater emphasis on scholarly research at these institutions is likely to prevent it from being a significant factor.

Although this study has examined electronic full-text databases and interlibrary borrowing from the standpoint of a large academic research library, the results of this and other studies suggest that the impact of these databases within a smaller academic library may be even greater. Users at academic libraries with smaller journal collections may find a greater percentage of potential borrowing requests available electronically. Despite license restrictions which will generally allow users to access only the electronic journal titles to which their library subscribes, smaller academic libraries may be able to offer their users an expanded range of titles and reduce their interlibrary workload through membership in a consortium. 
The role of electronic full-text databases among the resources in an academic library is still evolving. Undoubtedly, there is a learning curve or time lag before users can be informed of this new resource, taught to use it, and made comfortable enough with electronic databases to regularly incorporate them in their research. This study demonstrates that in a typical academic research library there currently are still not enough journal titles available in electronic full-text for there to be a significant reduction in the volume of interlibrary borrowing requests. However, the study also proves that there are real opportunities for users to obtain needed articles without having to use traditional interlibrary borrowing services. Even if the growth in availability of full-text articles remains constant, which is unlikely given their growing popularity, as users become more familiar with these databases they are more likely to use them as an alternative source for journal articles not owned by their library. This should further spur the growth in available content and eventually enhance the role of electronic full-text as a substitute for traditional interlibrary borrowing. 


\section{Appendix A}

\section{Electronic Full-Text Databases Used in the Study}

This appendix provides brief summaries of the electronic full-text

databases used in preparing this study. They are typical of the databases that are likely to be available at a large academic research library. The summaries are based on descriptions provided by the vendors themselves, supplemented with personal comments on their perceived usefulness.

ABI/Inform Global - A product of UMI ProQuest Direct, this database contains articles that are primarily related to business, marketing, and finance, although I found articles from journals outside these realms. Articles either in full-text, fulltext plus graphics, or page image format (using Adobe Acrobat) are available in some cases as far back as 1987. Searching by journal title yields a list of each available issue from which the user can link to an alphabetical listing of the contents. This can be very helpful when the user's cite is incomplete. This database is easy to use and contained a large percentage of the articles found to be available in this study.

EBSCOhost 3.1 - Using the MasterFILE Premier database, users have access to over 1,810 periodical titles containing full-text articles back to 1990. Most of the currently available articles are full-text only, but with version 3.1 EBSCO is now offering PDF image formats as well. This database provided the widest range of titles by discipline of all the databases examined in this study. Among the subject areas included are the social sciences, general sciences, health, education and 
business. This database is less forgiving to users with incomplete citations, but otherwise is well-designed and easy to use. The majority of full-text request matches in this study were found using this database.

JSTOR - The Journal Storage project contains files back to the last century for a select number of scholarly journals. Articles are available in image format and are also linked to searchable full-text. Currently there are 101 available titles, with more anticipated for inclusion. This type of database is a partial answer to the lack of a comprehensive backfile. The primary drawback to the average user is the lack of recent articles in the database, due to a "moving wall" which prohibits the inclusion of articles from the three most recent years. Because of its selective nature, only one full-text article match was found using this database. 


\section{Works Cited}

Adams, Judith A. and Sharon C. Bonk. 1995. Electronic information technologies and resources: Use by university faculty and faculty preferences for related library services. College \& Research Libraries 56 (March): 121123.

Baker, Shirley K. and Mary E. Jackson. 1993. Maximizing access, minimizing cost: A first step toward the information access future. Washington, DC: Association of Research Libraries.

Bancroft, Audrey and others. 1998. A forward-looking library use survey: WSU libraries in the $21^{\text {st }}$ Century. The Journal of Academic Librarianship (May): 216-223.

Bane, Adele F. 1995. Business periodicals ondisc: How full-text availability affects the library. Computers in Libraries (May): 54-56.

Beam, Joan. 1997. Document delivery via UnCover: Analysis of a subsidized service. Serials Review 23 (Winter): 1-14.

Bjornshauge, Lars. 1999. Opinion paper: From interlending and document delivery to cooperative collections and document access. Interlending \& Document Supply 27 (1): 30-32.

Ellis, Steven, Pamela Simpson, and Lynne Stuart. 1998. Understanding technological change: Electronic text and university libraries. Technical Services Quarterly 16 (1): 43-55.

Everett, David. 1993. Full-text online databases and document delivery in an Academic library: Too little, too late? Online: 22-24.

1993. Full-text online databases as a document delivery system: The unfulfilled promise. Journal of Interlibrary Loan \& Information Supply 3 (3): 17-25.

Fong, Yem Siu. 1996. From paper forms to electronic transmission: The evolution of interlibrary loan electronic technologies. Chapter 2 of Managing resource sharing in the electronic age. New York: AMS Press. 
Gyeszly, Suzanne D. and Gary Allen. 1991. Effects of online periodical indexes on interlibrary loan services and collection development. Journal of Interlibrary Loan \& Information Supply 1 (3): 39-48.

Haricombe, Lorraine J. 1998. Introduction. Library Trends 47 (Summer): 1-6.

Jackson, Mary E. 1998. Loan stars: ILL comes of age. Library Journal 123 (1 February): 44-47.

Jones, Daniel H. 1998. Electronic publishing: The library's view. Serials Librarian 34: 191. Quoted in John Webb. 1998. Managing licensed networked electronic resources in a university library. Information Technology and Libraries (December): 198-206.

Khalil, Mounir A. 1996. Exploiting electronic and networked information sources by end users. In Proceedings of the Seventeenth National Online Meeting, ed. Martha E. Williams, 189-200. Medford, NJ: Information Today.

Machovec, George S. 1997. Electronic journal market overview - 1997. Serials Review 23 (Summer): 31-44.

McKay, Sharon Cline. 1999. Accessing electronic journals. Database (Apil/May): 16-23.

Meadows, Jack. 1996. Opinion paper: Surveying electronic journals. Interlending \& Document Supply 24 (4): 32-33.

Medina, Sue O. and William C. Highfill. 1996. Promises and perils for traditional interlibrary loan services. In Advances in Collection Development and Resource Management, vol. 2, ed. Thomas W. Leonhardt, 27-47. Greenwich, CT: JAI Press.

Milton, Suzanne. 1998. Has the availability of electronic journals in full text affected interlibrary loan usage?: An EWU case study. ALKI (March): 18-19.

Naylor, Ted E. 1997. The cost of interlibrary loan services in a medium-sized academic library. Journal of Interlibrary Loan \& Information Supply 8 (2): 51-61.

Pack, Thomas. 1996. Trends in digital document delivery. In Proceedings of the Seventeenth National Online Meeting, ed. Martha E. Williams, 287-292. Medford, NJ: Information Today.

Prabha, Chandra and Elizabeth C. Marsh. 1997. Commercial document suppliers: 
How many of the ILL/DD periodical article requests can they fulfill? Library Trends 45 (Winter): 551-568.

Prabha, Chandra and Gay N. Dannelly. 1997. Introduction. Library Trends 45 (Winter): 367-372.

Prowse, Stephen. 1998. Trends and developments in interlending and document delivery in the UK. Interlending \& Document Supply 26 (2): 83-92.

Rabine, Julie and Linda Rich. 1998. Managing electronic journals in times of change. Serials Librarian: 279-283. Quoted in John Webb. 1998. Managing licensed networked electronic resources in a university library. Information Technology and Libraries (December): 198-206.

Robbins, Rachel and John B. Harer. 1991. The impact of the Wilson MultiDatabase Access Product on ILL requests and current periodical use. Journal of Interlibrary Loan \& Document Delivery 1 (4): 17-29.

Rogers, Michael. 1998. ICOLC releases statement on the purchase of electronic information. Library Journal (1 May): 25.

Sellers, Minna and Joan Beam. 1995. Subsidizing unmediated document delivery: Current models and a case study. Journal of Academic Librarianship (November): 459-466.

Smith, Jane. 1998. Document delivery and beyond. Technical Services Quarterly 16 (2): $15-24$.

Technical Services Quarterly 16(1): 76-77. 1998. Three subscription agents sign on with FirstSearch Electronic Collections Online.

Tenopir, Carol. 1999. Recapturing the past online. Library Journal, 1 February, 39.

Tenopir, Carol and Jeff Barry. 1999. Data dealers forging links. Library Journal, 15 May, 40-43.

Webb, John. 1998. Managing licensed networked electronic resources in a university library. Information Technology \& Libraries (December): 198-206. 